\title{
Anatomic Stage IIB Breast Cancer AJCC v8
}

National Cancer Institute

\section{Source}

National Cancer Institute. Anatomic Stage IIB Breast Cancer A/CC v8. NCI Thesaurus.

Code 139540.

Stage IIB includes: (T2, N1, M0); (T3, N0, M0). T2: T umor measuring more than $20 \mathrm{~mm}$, but not more than $50 \mathrm{~mm}$ in greatest dimension. T3: Tumor measuring more than 50 $\mathrm{mm}$ in greatest dimension. N0: No regional lymph node metastasis is identified or isolated tumor cell clusters (IT CS) are identified only. N1: T umor with micrometastases; or metastases in 1-3 axillary lymph nodes; and/or clinically negative internal mammary nodes with micrometastases or macrometastases by sentinel lymph node biopsy. M0: No clinical or radiog raphic evidence of distant metastases. Imaging studies are not required to assign the M0 category. (AJCC 8th ed.) 